periodontal disease were randomised to either placebo (PBO) or ALN $70 \mathrm{mg}$ once weekly.

Results The overall and upper gastrointestinal (GI) safety and tolerability profile of ALN after one year of treatment was very favourable compared to placebo.

Table 1:

\begin{tabular}{|c|c|c|c|c|c|}
\hline $\begin{array}{l}\text { Adverse } \\
\text { Events } \\
\text { (\% } \\
\text { patients) }\end{array}$ & $\begin{array}{l}\text { ALN (N = } \\
167)\end{array}$ & $\begin{array}{l}\mathrm{PBO}(\mathrm{N}= \\
168)\end{array}$ & $\begin{array}{l}\text { Upper GI Adverse } \\
\text { Events } \\
\text { (\% patients) }\end{array}$ & $\begin{array}{l}\text { ALN }(N= \\
167)\end{array}$ & $\begin{array}{l}\mathrm{PBO}(\mathrm{N}= \\
168)\end{array}$ \\
\hline Any & 81.4 & 84.5 & Any upper GI & 10.8 & 11.9 \\
\hline $\begin{array}{l}\text { Drug-related } \\
\text { [1] }\end{array}$ & 9.0 & 11.9 & Drug-related [1] & 4.2 & 6.5 \\
\hline Discontinued & 2.4 & 3.0 & Abdominal pain & 4.8 & 4.8 \\
\hline Serious [2] & 5.4 & 4.8 & Dyspepsia & 2.4 & 4.8 \\
\hline
\end{tabular}

[1] Drug-related indicates that the investigator considered the event possibly related to study drug while still blinded to treatment allocation.

[2] Serious adverse events include those requiring hospitalisation or causing death

Conclusion In summary, 1-year data show that ALN 70 mg once weekly was very well tolerated in men and women with moderate to severe periodontal disease.

\section{SAT0168 RISEDRONATE IS ASSOCIATED WITH A LOWER INCIDENCE OF GASTRIC ULCERS THAN ALENDRONATE: RESULTS FROM TWO COMPARATIVE STUDIES}

${ }^{1} \mathrm{JK}$ Marshall, ${ }^{2} \mathrm{JM}$ Provenza, ${ }^{3} \mathrm{AB}$ Thomson, ${ }^{1} \mathrm{RH}$ Hunt, ${ }^{4} \mathrm{KJ}$ Bos, ${ }^{4} \mathrm{MA}$ Blank. ${ }^{1}$ Division of Gastroenterology, McMaster University Medical Centre, Hamilton; '2Gastrointestinal Specialists AMC, Shreveport, Louisiana; ${ }^{3}$ University of Alberta, Edmonton, Canada; ${ }^{4}$ Procter \& Gamble Pharmaceuticals, Mason, USA

\subsection{6/annrheumdis-2001.655}

Background Bisphosphonates (BPs) are effective treatments for osteoporosis, but some have been associated with GI injury.

Objectives We compared the incidence of gastric ulcers after treatment with risedronate (RIS), a pyridinyl BP, and alendronate (ALN), a primary amino BP, in 2 similar endoscopic studies.

Methods In both studies, healthy postmenopausal women were randomised to receive RIS $5 \mathrm{mg}$ or ALN $10 \mathrm{mg}$ daily for 14 days. Subjects received ALN as original round tablets in Study 1 and as wax-polished oval tablets in Study 2. In Study 2, subjects were stratified by Helicobacter pylori (HP) status before randomization. Evaluator-blind assessment of the esophageal, gastric, and duodenal mucosa was performed at baseline and on Days 8 and 15 of each study.

Results In both studies, the overall incidence of gastric ulcers $>3$ $\mathrm{mm}$ was significantly lower in the RIS group than in the ALN (Table 1). Mean gastric erosion scores were significantly lower in the RIS group than in the ALN group at Day 8 and 15 (p < 0.001 ) in both studies. Mean esophageal and duodenal endoscopy scores were similar in the 2 groups at Days 8 and 15 . Esophageal ulcers were noted in none of the evaluable subjects in the RIS group and in 3 in the ALN group in Study 1, and in 1 evaluable subject in the RIS group and 2 in the ALN group in Study 2. Duodenal ulcers were noted in 2 evaluable subjects in the RIS group and 1 in the ALN group in Study 1 and in none of the evaluable subjects in Study 2. In Study 2, HP infection did not increase the incidence of BP-related GI injury.

\begin{tabular}{llllll} 
Abstract & SAT0168 Table 1 & & & \\
\hline & RIS 5 mg & RIS 5 mg & ALN 10 mg & ALN 10 mg & P-value \\
N & (\%) & N & n (\%) & \\
\hline Study 1 & 221 & $9(4.1)$ & 227 & $30(13.2)$ & $<0.001$ \\
Study 2 & 300 & $18(6.0)$ & 297 & $36(12.1)$ & 0.013 \\
\hline
\end{tabular}

Conclusion In 2 large, comparative studies in which RIS and ALN were given at doses for the treatment of osteoporosis, the incidence of gastric ulcers was significantly lower among RIStreated subjects than among ALN-treated subjects. Results were consistent in the 2 studies despite the difference in the shape and polish of the ALN tablets used. These findings support the hypothesis that BPs differ in their potential to produce upper GI mucosal damage.

\section{SAT0169 INFLUENCE OF VITAMIN D RECEPTOR (VDR) GENOTYPE IN THE BONE LOSS INDUCED BY CORTICOSTEROID THERAPY}

M Gantes, A Arteaga, Y Barrios, E Uruburu, I Ferraz, B Rodríguez-Lozano, A Alvarez, E Trujillo, T González. Rheumatology, Hospital Universitario de Canarias, La Laguna, Spain

\subsection{6/annrheumdis-2001.656}

Background Corticosteroid therapy (CST) is a risk factor for developing decreased bone mineral density (BMD). Previous studies suggest that VDR genotipe is involved on loossing BMD. Objectives To investigate the influence of VDR genotype in changes of BMD induced by CST.

Methods In 53 patients (age 41,7 $\pm 12,6$ ) without osteoporosis, who received a dose greater than $5 \mathrm{mg}$ daily of prednisone or equivalent for 3 months (mean dose 1,9 g). VDR genotypes were determined by PCR to demonstrate the presence (b) or absence (B) of a restriction target for Bsm I, in intron 7. Bone mineral density (BMD) by DEXA at spine, femoral neck (FN) and Ward's triangle (WT) were measured baseline and 3 months after CST and expressed as a Z- score.

Results The BMD was reduced 3 months after CST (cumulative steroid dosage, mass index, and age was adjusting) without significant difference in both VDR groups: bb, and bB-BB; (Zscore before/ 3 months after) at Spine: $0,40 / 0,17 \mathrm{bb} ; 0,32 / 0,10$ bB-BB; FN: 0,87/0,75 bb; 0,40/0,15 bB-BB; WT: 0,84/0,86 bb; $0,22 / 0,14 \mathrm{bB}-\mathrm{BB}$. However, when the patients were adjusting to receive more or lesser than $1,3 \mathrm{~g}$ cumulative dose, those patients had bb genotype and greater dose had significant lower BMD at WT $(\mathrm{p}<0,05)$, respective bB- BB genotypes.

Conclusion Data suggest that the VDR genotype identifies the patients with greater risk to bone loss when high corticosteroids dose is used.

\section{SAT0170 RISEDRONATE REDUCES THE RISK OF NEW VERTEBRAL FRACTURES IN 1 YEAR IN POSTMENOPAUSAL WOMEN ON CORTICOSTEROID THERAPY}

${ }^{1} \mathrm{RF}$ Laan, ${ }^{2} \mathrm{C}$ Benhamou, ${ }^{3} \mathrm{H}$ Taggart, ${ }^{4} \mathrm{E}$ Sod. ${ }^{1}$ Department of Rheumatology, University Medical Center Nijmegen, Academisch Ziekenhuis, Nijmegen, NB, Netherlands; ${ }^{2}$ Hopital La Source, Orleans, France; ${ }^{3}$ Belfast City Hospital, Belfast, UK; ${ }^{4}$ Procter \& Gamble Pharmaceuticals, Mason, OH, USA

10.1136/annrheumdis-2001.657 